\title{
Pemanfaatan Tanaman Pangi (Pangium Edule Reinw) pada Lahan Agroforestri Desa Watu Toa Kecamatan Marioriwawo Kabupaten Soppeng
}

\author{
Munawwarah Nawir ${ }^{1}$, Ira Taskirawati2, ${ }^{2 *}$ Baharuddin Baharuddin² \\ ${ }^{1}$ Mahasiswa Fakultas Kehutanan Universitas Hasanuddin, Makassar \\ 2Staf Pengajar Fakultas Kehutanan Universitas Hasanuddin \\ *E-mail: tasqira@unhas.ac.id
}

\begin{abstract}
Pangi (Pangium edule Reinw) is a type of commodity of Non-Timber Forest Product group, which all parts of this plant can be utilized. Pangi crops grown on agroforestry land is one of the preservation of this plant in order to be utilized sustainably. To fulfill the necessities of life, the people of Desa Watu Toa manage their land by making it as an agroforestry land and planting seasonal crops, fruits and forestry crops. One type of forest crops planted is Pangi. This study aims to identify the utilization of pangi by the community in Watu Toa Village, Marioriwawo District, Soppeng District. Survey (direct observation and questioner) and interview are the methods used in this research. The data obtained are arranged in table form and described in descriptions to describe the utilization of pangi by farmers in Watu Toa Village, Marioriwawo Subdistrict, Soppeng Regency. There are four hamlets in the village of Watu Toa, but this research is only conducted on Dusun Masumpu and Dusun Jampu-jampu. In both villages, there is a pangi plant on agroforestry land managed by farmers. The area of agroforestry in both hamlets is on average between 0.25-0.50 ha. Watu Toa Village Farmers only utilizes six products produced from pangi plant, namely construction materials (stems); fish poison (skin); natural pesticides (leaves), antiseptics (leaves), vegetables (young leaves); as well as fruit / pangi as an ingredient that can be cake, tempeh, vegetable ise 'pangi, vegetable Lope' pangi, and cooking spice (kluwak).
\end{abstract}

Keywords: Utilization; Pangium Edule; Agroforestry

DOI: http://dx.doi.org/10.24259/jhm.v9i2.3039

\section{PENDAHULUAN}

Hasil Hutan Bukan Kayu (HHBK) merupakan bagian dari ekosistem hutan yang memiliki peranan yang beragam, baik terhadap lingkungan alam maupun terhadap kehidupan manusia (Suhesti dan Hadinoto, 2015). Hasil hutan bukan kayu didefiniskan sebagai segala sesuatu yang bersifat material (bukan kayu) yang dapat dimanfaatkan dari keberadaan hutan, seperti rotan, bambu, damar, getah-getahan, kulit kayu, arang bambu, kayu bakar dan sebagainya. Produk hasil hutan bukan kayu terdiri atas bagian-bagian dari tanaman yang memiliki nilai atau potensi yang tinggi, baik secara ekonomi, ekologi maupun sosial sehingga bunga, biji, daun, buah serta akar dapat dimanfaatkan (Wahyudi, 2013; Affandi dkk, 2017). Secara ekologis, masyarakat mengerti dan memahami bahwa komoditas hasil hutan bukan kayu merupakan bagian dari ekosistem hutan yang memiliki fungsi yang penting, tidak hanya bagi hutan tetapi juga bagi masyarakat.

Pangi (Pangium edule Reinw) merupakan salah satu hasil hutan bukan kayu yang berpotensi untuk dikembangkan pada lahan agroforestry. Pangi merupakan jenis komoditas kelompok nabati, yang semua bagian pada tanaman pangi dapat dimanfaatkan. Buah atau biji tanaman pangi memiliki nilai ekonomi karena dapat dijadikan sayur ataupun kue tradisional, selain itu batang sebagai bahan kontruksi sedangkan biji dan daunnya dapat dimanfaatkan.

Tanaman pangi telah dikembangkan pada lahan agroforestri. Desa Watu Toa merupakan salah satu desa dimana masyarakatnya telah mengembangkan tanaman ini dengan model agroforestri pada lahan garapannya. Agroforestri adalah pola usaha tani produktif yang tidak saja mengetengahkan kaidah konservasi tetapi juga kaidah ekonomi. Agroforestri sebagai sistem 
penggunaan lahan makin diterima oleh masyarakat karena menguntungkan bagi pembangunan sosial ekonomi, sebagai ajang pemberdayaan masyarakat petani dan pelestarian sumber daya alam serta pengelolaan lingkungan daerah pedesaan (Soedjoko dan Suryatmojo, 2002).

Tanaman pangi yang ditanam khususnya pada lahan agroforestri Masyarakat Desa Watu Toa Kecamatan Marioriwawo Kabupaten Soppeng memiliki potensi yang sangat besar. Namun, masyarakat Desa Watu Toa hanya memanfaatkannya untuk keperluan tertentu. Penelitian ini bertujuan untuk mendapatkan Informasi mengenai pemanfaatan tanaman pangi oleh masyarakat Desa Watu Toa perlu diketahui. Data tersebut dapa dijadikan bahan kajian mengenai pemanfaatan lain dari tanaman pangi yang dapat dikembangkan oleeh masyarakat Desa Watu Toa.

\section{METODE PENELITIAN}

\subsection{Metode Pengumpulan Data}

Metode yang digunakan dalam penelitian ini adalah metode Survey (direct observation dan questioner) dan interview. Responden pada penelitian ini adalah petani Desa Watu Toa yang mempunyai tanaman pangi pada lahan agroforestrinya yaitu 31 responden di Dusun Masumpu dan 40 responden di Dusun Jampu-jampu, sehingga total keseluruhan jumlah 71 responden.Data yang dikumpulkan pada penelitian ini berasal dari dua sumber, yaitu data primer dan data sekunder. Pengambilan data primer dilakukan dengan cara: Direct Observation yaitu pengumpulan data yang dilakukan untuk mendapatkan informasi secara langsung dilapangan mengenai tanaman pangi dan pemanfaatan oleh petani; Questioner yaitu sejumlah pertanyaan tertulis yang digunakan untuk memperoleh informasi dari responden secara terarah mengenai pemanfaatan pangi oleh petani; dan Interview, dilakukan dengan cara tanya jawab sambil bertatap muka langsung dengan masyarakat yang dijadikan sampel penelitian guna mendapatkan informasi tentang pemanfaatan pangi yang ditanam. Data sekunder terdiri atas keadaan fisik (luas dan letak hutan).

\subsection{Analisis Data}

Data yang diperoleh disusun dalam bentuk tabel. Analisis data penelitian ini dijelaskan secara deskripsi untuk mendapatkan gambaran pemanfaatan pangi oleh petani.

\section{HASIL DAN PEMBAHASAN}

\subsection{Deskripsi Lahan Agroforestri di Desa Watu Toa Kabupaten Soppeng}

Total luas wilayah Desa Watu Toa 2900 ha, terdiri atas empat dusun yaitu Dusun Masumpu, Dusun Tokebbeng, Dusun Jampu-jampu dan Dusun Tompoe. Jenis tanaman yang ada pada setiap lahan agroforestri sangat beragam. Untuk pemenuhan kebutuhan masyarakat menerapkan pada lahan agroforestri acak dengan menanam jenis tanaman pertanian dengan tanaman kehutanan. Petani cenderung mengkombinasikan jenis tanamannya cepat tumbuh menjadikan petani memilih jenis tanaman tersebut sehingga dapat mengganti tanaman yang sudah ditanam sebelumnya dengan tanaman yang baru jika sewaktu-waktu nanti tanaman tersebut tidak menguntungkan akibat kondisi iklim ataupun alasan lainnya. Terdapat 15 jenis tanaman yang terdapat pada lahan agroforestri di Desa Watu Toa. Komposisi jenis tanaman ditunjukkan pada Tabel 1.

\subsection{Luas Lahan Responden di Desa Watu Toa Kabupaten Soppeng}

Luas lahan merupakan salah satu faktor produksi yang ketersediaannya sangat penting dan berpengaruh terhadap komoditas serta produksi yang dihasilkan. Petani yang memiliki lahan usahatani yang luas akan memperoleh hasil produksi yang besar. Adapun rincian luas lahan agroforestri dapat dilihat pada Tabel 2 . 
Tabel 1. Komposisi Jenis tanaman yang ada pada Lahan Agroforestri di Desa Watu Toa

\begin{tabular}{cl}
\hline No & \multicolumn{1}{c}{ Nama Tanaman } \\
\hline 1 & Pangi (Pangium edule Reinw) \\
\hline 2 & Kemiri (Aleurites moluccana) \\
\hline 3 & Jati putih (Gmelina arborea) \\
\hline 4 & Sukun (Artocarpus communis) \\
\hline 5 & Mangga (Mangifera indica) \\
\hline 6 & Pinang ( Areca catechu) \\
\hline 7 & Jambu Mente (Anacardium occidentale) \\
\hline 8 & Aren (Arenga pinnata) \\
\hline 10 & Kakao (Theobroma cacao) \\
\hline 11 & Nangka ( Artocarpus heterophyllus) \\
\hline 12 & Pisang (Zingiber officinale) \\
\hline 13 & Jagung (Zea mays) \\
\hline 14 & Singkong (Manihot esculenta) \\
\hline 15 & Pepaya (Carica papaya) \\
\hline
\end{tabular}

Tabel 2. Luas Kepemilikan Lahan Responden Agroforestri Pangi di Desa Watu Toa Kabupaten Soppeng

\begin{tabular}{cccccc}
\hline No & $\begin{array}{c}\text { Luas Lahan } \\
\text { (ha) }\end{array}$ & \multicolumn{2}{c}{ Dusun Masumpu } & \multicolumn{2}{c}{ Dusun Jampu-jampu } \\
\cline { 3 - 6 } & & $\begin{array}{c}\text { Jumlah } \\
\text { Responden }\end{array}$ & $\begin{array}{c}\text { Persen } \\
(\%)\end{array}$ & Jumlah Responden & Persen (\%) \\
\hline 1 & $<0,25$ & 13 & 42 & 0 & 0 \\
\hline 2 & $0,25-0,50$ & 15 & 48,3 & 18 & 45 \\
\hline 3 & $0,50-1$ & 3 & 9,7 & 14 & 35 \\
\hline 4 & $1-2$ & 0 & 0 & 8 & 20 \\
\hline & Jumlah & 31 & 100 & 40 & 100 \\
\hline
\end{tabular}

Tabel 2. menunjukkan bahwa sebanyak $48,3 \%$ petani di Dusun Masumpu dan Dusun Jampu-jampu sebanyak $45 \%$ petani memiliki luas lahan agroforestri antara 0,25 sampai 0,50 ha. Lahan agroforestri yang dikembangkan oleh responden di Desa Watu Toa adalah tanaman pangi secara sengaja dan tumbuh alami pada lahan agroforestri. Pemanfaatan lahan dengan agroforestri membuat tingkatan tajuk yang bervariasi dalam lahan tersebut, hal ini akan sangat baik terhadap pertumbuhan tanaman dan lingkungan. Responden juga memanfaatkan lahannya yang masih kosong demi mendapatkan hasil panen yang beragam dalam satu luasan lahan untuk memperbanyak hasil panen. Suharjito, dkk (2003) menyatakan pengaruh luas lahan terhadap pilihan praktek agroforestri tergantung pada faktor ketersediaan alternatif sumber-sumber ekonomi keluarga dan pola komposisi jenis tanaman menurut intensistas waktu panen. Responden menanam tanaman semusim dengan mengkombinasikan tanaman. Hal ini sejalan dengan pernyataan Kang et al. (1984) dalam (Millang, 2010) yang menyatakan bahwa praktek pertanian agroforestri menghasilkan banyak manfaat termasuk produktivitas yang tinggi dan menjaga kesuburan tanah sehingga dapat meningkatkan pendapatan masyarakat di lahan agroforestrinya 


\subsection{Pemanfaatan Tanaman Pangi}

\section{a. Jenis-jenis Pemanfaatan Tanaman Pangi di Desa Watu Toa Kabupaten Soppeng}

Tanaman pangi dapat dimanfaatkan dengan cara diolah dalam beberapa bentuk produk. Masyarakat Desa Watu Toa hanya memanfaatkan enam produk yang dihasilkan dari tanaman pangi, yaitu sebagai batang sebagai bahan konstruksi dan racun ikan (kulit); daun sebagai pestisida alami, obat (antiseptik), dan sayur (daun muda); serta buah/biji pangi sebagai bahan makan yang dapat berupa kue, tempe, sayur ise' pangi dan Lope' pangi, dan bumbu masak (kluwak). Adapun jenis-jenis pemanfaatan tanaman pangi di Desa Watu Toa dapat dilihat pada Tabel 3 .

Pemanfaatan pertama dari tanaman pangi di Desa Watu Toa adalah menjadikan batang tanaman pangi sebagai bahan konstruksi. Sebanyak $25 \%$ responden yang memanfaatkan batang tanaman pangi sebagai bahan kontruksi. Menurut Arini (2012) menyatakan, Kayu pangi dikelompokkan dalam kayu kelas II dengan keawetan sedang dan berat jenis 0,31 . Penggunaan kayu pangi sebagai bahan kontruksi bangunan ditunjang dengan rumah masyarakat di desa tersebut yang rata-rata terbuat dari kayu. Selain sebagai bahan kontruksi, kayu pangi juga cocok digunakan untuk bahan meubel seperti furniture meja, lemari dan lain-lainnya.

Tabel 3. Jenis-jenis Pemanfaatan Tanaman Pangi Desa Watu Toa Kabupaten Soppeng

\begin{tabular}{|c|c|c|c|c|c|c|}
\hline \multirow[b]{2}{*}{ No } & & \multirow[b]{2}{*}{ Jenis Pemanfaatan } & \multicolumn{2}{|c|}{ Jumlah Responden yang Memanfaatkan } & \multirow{2}{*}{$\begin{array}{c}\text { Total } \\
\text { Responden }\end{array}$} & \multirow{2}{*}{$\begin{array}{c}\text { Persentase }(\% \\
\text { Responden }\end{array}$} \\
\hline & & & Dusun Masumpu & $\begin{array}{c}\text { Dusun Jampu- } \\
\text { jampu }\end{array}$ & & \\
\hline \multirow[t]{2}{*}{1} & Batang/Kulit & 1 Bahan konstruksi & 10 & 8 & 18 & 25 \\
\hline & batang & 2 Racun ikan & 10 & 6 & 16 & 22 \\
\hline \multirow[t]{3}{*}{2} & & 3 Pestisida alami & 17 & 14 & 31 & 43 \\
\hline & Daun & 4 Sayur (daun muda) & 12 & 13 & 25 & 35 \\
\hline & & 5 Obat (antiseptik) & 5 & 5 & 10 & 14 \\
\hline 3 & Buah/Biji & $\begin{array}{l}6 \text { Bahan makanan (kue } \\
\text { (dodol), tempe, sayurise' } \\
\text { pangi dan lope'pangi, } \\
\text { bumbu masak (kluwak)) }\end{array}$ & 28 & 36 & 64 & 90 \\
\hline
\end{tabular}

Pemanfaatan kedua dari tanaman pangi adalah sebag ai racun ikan. Racun ikan ini juga diperoleh dengan memanfaatkan batang serta kulit batang. Sebanyak $22 \%$ responden di Desa Watu Toa yang memanfaatkan batang kayu pangi sebagai racun ikan. Batang dan kulit pangi yang biasanya digunakan sebagai racun ikan adalah serbuk kayu yang diperoleh dari sisa penebangan pohon pangi. Serbuk yang terdiri atas campuran batang dan kulit kayu pangi tersebut diremas-remas dan kemudian ditaburkan ke dalam sungai. Kandungan sianida pada batang dan kulit tanaman pangi dapat mematikan ikan. Yuningsih (2008) menyatakan, selain batang dan kulit, biji pangi (daging dan kulit lunak) juga mempunyai kandungan sianida cukup tinggi. Kandungan sianida dalam tumbuhan pangi dipengaruhi oleh kondisi tanah, musim, dan struktur bijinya.

Pemanfaatan ketiga adalah sebagai pestisida alami. Pemanfaatan daun sebagai pestisida alami dilakukan 43\% responden di Desa Watu Toa. Salaki, dkk (2012) menyatakan khususnya pada bagian daun terdapat ekstrak heksana yang dapat menjadi antifeedant (anti makan), sebagai pencegahan dan perlindungan tanaman pangan dari serangan Plutellaxylostella. Senyaw antifeedant tidak membunuh, mengusir atau menjerat serangga hama, tetapi hanya menghambat selera makan dari serangga tersebut sehingga tanaman pangan dapat terlindungi dari serangan hama. Cara masyarakat Desa Watu Toa menggunakan daun sebagai pestisida alami adalah dengan cara menggosokkan daun pada pohon yang mempunyai hama yang bisanya berupa semut rangrang ataupun serangga lainnya. Masyarakat Desa Watu Toa belum mengolah daun pangi menjadi cairan pestisida alami untuk diperjual belikan. 
Pemanfaatan ke empat dari tanaman pangi adalah dengan menjadikan daun muda dari tanaman pangi sebagai bahan baku pembuatan sayur. Sebanyak $35 \%$ responden yang memanfaatkan daun muda tanaman pangi sebagai sayur. Cara pemanfaatan daun muda pangi sebagai sayur adalah daun muda di rendam dengan menggunakan air dingin. Selama proses perendaman, dilakukan beberapa kali pergantian air. Jika dalam proses perendaman sudah tidak ada warna merah pada air hasil rendaman tersebut, maka daun siap untuk dimasak.

Pemanfaatan kelima dari tanaman pangi adalah menjadikan daun pangi sebagai obat antiseptik sebanyak $14 \%$ responden yang telah memanfaatkan daun tanaman pangi sebagai obat antiseptik. Khasiat daun pangi ini adalah dapat membersihkan luka luar dan gatal-gatal pada kulit. Cara pemanfaatannya adalah dengan menumbuk daun pangi dan membalurkannya pada luka. Menurut Pinto (2017) menyatakan daun pangi memiliki kandungan senyawa fitokimia sebagai antibakteri dan antiseptik, daun pangi yang direbus dapat pula digunakan sebagai pemusnah hama dan pencegah parasit.

Pemanfaatan terakhir dari tanaman pangi ini adalah pemanfaatan buah/biji sebagai bahan makanan. Pemanfaatan pangi sebagai bahan makanan adalah jenis pemanfaatan yang paling banyak dilakukan oleh masyarakat. Sebanyak $90 \%$ responden yang memanfaatkan buah/biji sebagai bahan makanan. Pemanfaatan buah/biji yang dijadikan bahan makanan tidak hanya untuk lauk pauk, namun juga dalam berbagai bentuk panganan (diversifikasi produk). Di Desa Watu toa, buah/biji pangi telah diolah sebagai dodol pangi, tempe, sayur ise' pangi dan lope' pangi dan bumbu masak (kluwak). Dodol pangi, merupakan panganan khas Kabupaten Soppeng. Dodol ini menggunakan daging pangi sebagai bahan utamanya dan dicampur dengan tepung beras ketan, kelapa dan gula merah atau gula pasir (BPDAS Jeneberang Walanae, 2006).

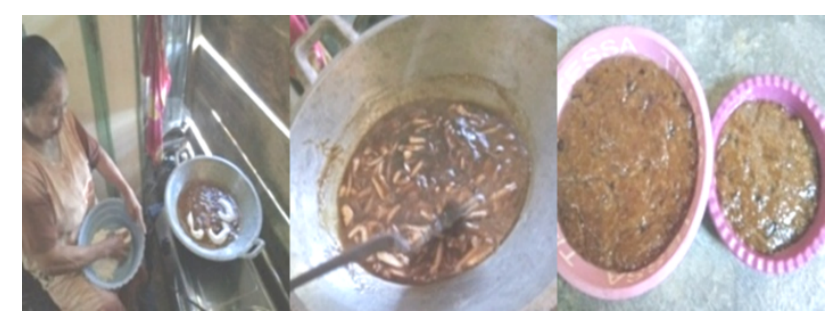

Gambar 1. Proses pembuatan kue (dodol pangi) oleh salah satu masyarakat di Dusun Jampujampu (Dokumentasi Pribadi, 2017).

Tempe, masyarakat di Desa Watu Toa menyebutnya tempe pangi (pijja' pangi). Tempe pangi memanfaatkan daging yang muda sebagai bahan baku utama. Pangi muda dikeluarkan dari batok yang keras lalu daging pangi yang muda tersebut dicampur sereh, bawang putih-merah dan garam lalu dibentuk memakai sendok selanjutnya di bungkus dengan menggunakan daun pisang atau plastik. Adonan yang sudah dibungkus tersebut kemudian dibiarkan selama dua malam.

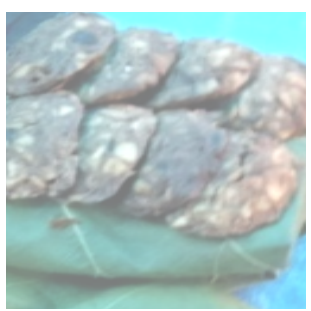

Gambar 2. Tempe pangi (Dokumentasi Pribadi, 2017).

Sayur ise' pangi dan lope'pangi, merupakan salah satu masakan khas daerah Soppeng. Cara membuat sayur ise pangi sebagai berikut daging yang muda diiris memanjang lalu di rendam. Setiap satu jam, air rendaman daging pangi di ganti. Proses ini dilakukan sampai air rendamannya sudah tidak berwarna merah. Warna merah menandakan bahawa daging pangi masih 
mengandung racun sianida. Cara lain menghilangkan racun yang ada di daging buah adalah melakukan perendaman di sungai yang mengalir. Berbeda dengan ise' pangi, sayur lope' pangi tidak menggunakan daging pangi sebagai bahan utama, tetapi bahan yang digunakan adalah bagian dari daging buah yang menempel pada batok biji. Bagian ini sering disebut lope' pangi oleh masyarakat Desa Watu Toa dan bagian ini tidak mengandung sianida seperti paga daging biji pangi. Sebelum di oleh lope' pangi di kupas karena menempel pada batok biji pangi dan dilakukan penjemuran sampai kering.

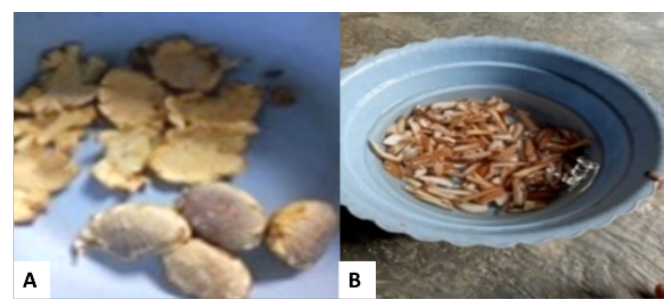

Gambar 3. (a) Ise' pangi siap diolah bahan sayur, (b) Pengupasan daging luar yang menempel dibatok biji pangi (lope' pangi) (Dokumentasi Pribadi, 2017)

Bumbu masak (Kluwak), Buah pangi sebagai bumbu masak (kluwak) merupakan salah satu jenis pemanfaatan buah pangi yang paling terkenal. Kluwak biasanya dijadikan pewarna makanan pada masakan konro dan rawon; sambal atau tumis kluwak, serta bumbu masakan pada ikan ataupun daging. Masyarakat Desa Watu Toa memanfaatkan buah yang masak dan biasanya jatuh dari pohon sebagai bahan baku pembuatan kluwak. Tanaman pangi mulai berbuah pada umur 15 tahun, dan berbuah secara terus menerus sepanjang musim. Buah dikumpulkan lalu disimpan selama 15 hari sehingga memudahkan biji keluar dari daging buah. Biji-biji pangi dicuci selanjutnya direbus selama 2 jam dengan api besar, lalu di dinginkan. Setelah buah pangi yang telah direbus dingin, dibuatkan lubang pada tanah dan biji-biji pangi ditumpuk dalam lubang tersebut. Sebelumnya, lubang tersebut dilapisi terlebih dahulu menggunakan karung goni / daun pisang agar mencegah bersentuhan langsung dengan tanah. Buah pangi ini ditanam selama 40 hari sampai 1 tahun lamanya. Setelah proses ini, buah pangi telah dapat dimanfaatkan sebagai kluwak.

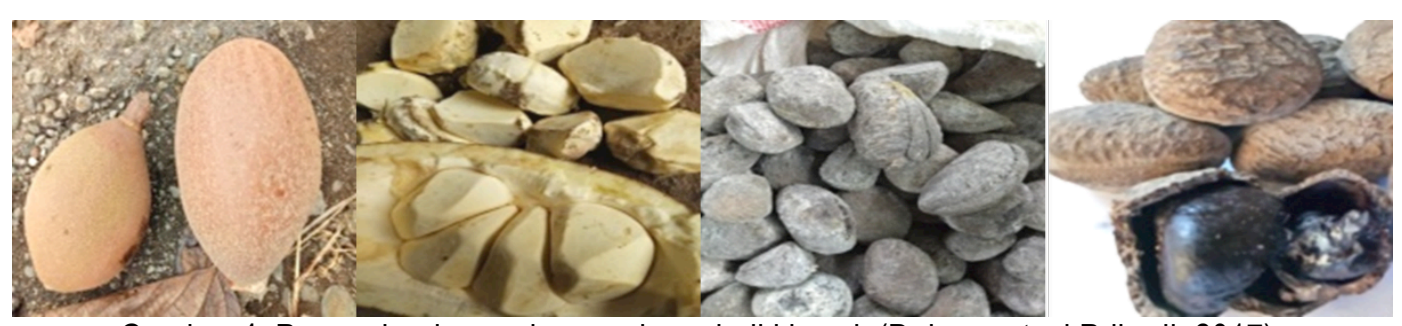

Gambar 4. Proses buah pangi sampai menjadi kluwak (Dokumentasi Pribadi, 2017).

\section{b. Persentase Pemanfaaatan dari Olahan Produk Buah/Biji Pangi di Pasarkan Masyarakat Desa Watu Toa Kabupaten Soppeng}

Pemanfaatan buah/biji pangi sebagai produk olahan bahan makanan adalah satu-satunya jenis pemanfaatan yang dipasarkan oleh masyarakat Desa Watu Toa. Jumlah responden yang memanfaatkan produk-produk tersebut dapat dilihat pada Tabel 4. Masyarakat Desa Watu Toa menjual buah/biji pangi dalam bentuk kluwak sebanyak $90 \%$ responden. Selain dalam bentuk kluwak, produk olahan berupa dodol juga banyak dipasarkan. Selain dodol dan kluwak, sayur (ise' pangi dan lope' pangi) dan tempe banyak ditemukan di jual di pasar-pasar tradisional. Hal tersebut sesuai dengan pernyataan Diniyanti dan Fauziyah (2012) yang menyatakan bahwa petani secara umum mengaku aspek ekonomi menjadi pendorong utama dalam pemilihan jenis atau 
membudidayakan suatu jenis tanaman. Dalam aspek ekonomi alasan masayarakat memadukan tanaman tersebut pada lahan agroforestri tanaman pangi ialah memilih tanaman yang memiliki jenis yang cepat produksi dan peluang pemasaran untuk pemenuhan dari segi aspek ekonomi.

Tabel 4. Jenis-jenispemanfaatan buah/biji pangi yang dipasarkan oleh masyarakat Desa WatuToa Kabupaten Soppeng

\begin{tabular}{|c|c|c|c|c|c|}
\hline \multirow{2}{*}{\multicolumn{2}{|c|}{ Jenis Pemanfaatan }} & \multicolumn{2}{|c|}{ Jumlah Responden yang Memanfaatkar } & \multirow{2}{*}{$\begin{array}{c}\text { Total } \\
\text { Responden }\end{array}$} & \multirow{2}{*}{$\begin{array}{c}\text { Persentase (\%) } \\
\text { Responden }\end{array}$} \\
\hline & & Dusun Masumpu & $\begin{array}{c}\text { Dusun Jampu= } \\
\text { jampu }\end{array}$ & & \\
\hline \multirow{4}{*}{$\begin{aligned} \text { Buah/Biij } & \text { Bahan } \\
& \text { makanan }\end{aligned}$} & 1 Kue (dodol) & 22 & 36 & 58 & 81 \\
\hline & 2 Tempe & 21 & 15 & 36 & 50 \\
\hline & 3 Sayur (ise'pangillope'pangi) & 23 & 34 & 57 & 80 \\
\hline & 4 Kluwak & 28 & 36 & 64 & 90 \\
\hline
\end{tabular}

c. Persentase Pemanfaaatan dari Olahan Produk Buah/Biji Pangi di Konsumsi Masyarakat Desa Watu Toa Kabupaten Soppeng

Buah/biji pangi yang dimanfaatkan sendiri oleh masyarakat Desa Watu Toa dapat dilihat diatas pada Tabel 5. Slah satu kreativitas masyarakat yaitu membuat Salah satu kreativitas masyarakat yaitu membuat dodol pangi.

Tabel 5. Jenis-jenis pemanfaatan buah/biji pangi yang dikonsumsi oleh masyarakat Desa Watu Toa Kabupaten Soppeng

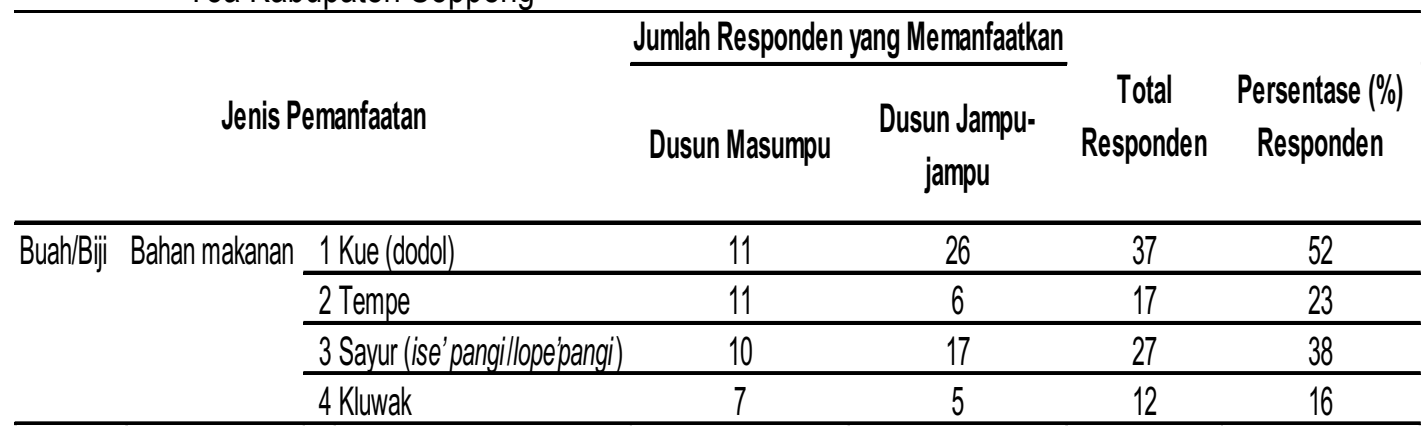

Tabel 5. menunjukkan bahwa $52 \%$ responden memanfaatkan buah/biji dengan menjadikannya panganan dodol pangi. Sayur (ise' Pangillope' Pangi) juga salah satu produk yang banyak dikonsumsi setelah dodol. Tempe dan kluwak merupakan dua olahan yang juga manfaatkan masing-masing. Tanaman pangi merupakan tanaman pelindung dan tanaman serbaguna hampir semua bagian dari tanaman ini dapat digunakan, meskipun jumlahnya sudah tidak banyak karena petani sudah mengganti dengan komoditi lain demi mendapatkan hasil yang beragam tetapi petani tetap mempertahankannya.

\section{KESIMPULAN}

Pemanfaatan tanaman pangi oleh masyarakat Desa Watu Toa terdiri atas Batang/ kulit batang : bahan kontruksi dan racun ikan; Daun: pestisida alami, obat antiseptik, dan sayur (daun muda); dan Buah/biji: diolah sebagai bahan makanan yang terdiri atas dodol, tempe, sayur ise' pangi, sayur lope' pangi dan bumbu masak (kluwak). 


\section{DAFTAR PUSTAKA}

Affandi, O., Zaitunah, A., \& Batubara, R. (2017). Potential Economic and Development Prospects of Non-Timber Forest Products in Community Agroforestry Land around Sibolangit Tourism Park. Forest and Society, 1(1), 68-77. doi:http://dx.doi.org/10.24259/fs.v1i1.1096

Arini, D.I.D. (2012) Potensi Pangi (Pangium edule Reinw) Sebagai BahanPengawet Alami dan Prospek Pengembangannya di Sulawesi utara. Info BPK Manado, Vol. 2, No. 2, Hal. 103 113.

BPDAS Jeneberang Walanae. (2006). Pangi (Pangium edule Reinw). Makassar: Balai Pengelolaan Daerah Aliran Sungai Jeneberang Walanae.

Diniyanti, D dan E. Fauziah. (2012). Pemilihan Jenis Tanamn Penyusun Hutan Rakyat Pola Agroforestry Berdasarkan Keputusan Petani di Kabupaten Tasikmalaya. Balai Penelitian Teknology Agroforestry.

Millang, S. (2010). Struktur, Komposisi, dan Pemilihan Jenis Komponen Sistem Agroforestry Di Desa Makuang, Kabupaten Mamasa. Jurnal SATRIA (Seri IImu Pengetahuan Alam) Edisi VI - Juli 2010.

Pinto, W.A. Lolo dan P.V.Y Yamlean. (2017). Identifikasi Kandungan Fitokimia dan Uji Kadar Bunuh Minimum Ekstrak Etanol Daun Pangi (Pangium edule Reinw) terhadap Pertumbuhan Bakteri Escherichia Coli. Jurnal ilmiah Farmasi. Program Studi Farmasi FMIPA UNSRAT Manado. Manado.

Salaki, C.L., E. Paendong dan J.Pelealu. (2012). Biopestisida dari Ekstrak Daun Pangi (Pangium sp.) terhadap Serangga Plutella xylostella di Sulawesi Utara. Eugenia, Vol18, No.3, Hal. 171177.

Soedjoko, S.A dan H. Suryatmojo. (2002). Pembangunan Kawasan Gunung Kidul dengan Konservasi Lahan yang Berwawasan Lingkungan. Makalah Lokakarya Pengembangan Agribisnis Berbasis Sumberdaya Lokal dalam Mendukung Pengembangan Ekonomi Kawasan Selatan Jawa. Malang.

Suharjito, D., L. Sundawati, Suryanto, S.R. Utami. (2003). Aspek Sosial Ekonomi dan Budidaya Agroforestry. ICRAF. Bogor

Suhesti, E dan Hadinoto. (2015). Hasil Hutan Bukan Kayu Madu Sialang Di Kabupaten Kampar (Studi Kasus : Kecamatan Kampar Kiri Tengah). Staf Pengajar Fakultas Kehutanan Universitas Lancang Kuning Pekanbaru. Riau.

Wahyudi. (2013). Buku Pegangan Hasil Hutan Bukan Kayu. Percetakan Pohon Cahaya. Yokyakarta.

Widiyanto, A. (2013). Agroforestry dan Peranannya dalam Mempertahankan Fungsi Hidrologi dan Konvervasi. National Graduate Institute fot Policy Studies. Tokyo. Japan.

Yuningsih. (2008). Kandungan dan Stabilitas Sianida dalam Tanaman Picung (Pangium edule Reinw) serta Pemanfaatannya. Balai Besar Penelitian Veteriner. 